\title{
Metacognitive Awareness And Its Relation To \\ Students' Academic Achievement: Time To Ponder Its Implication In Delivery of The Curriculum.
}

\section{Shahid Hassan}

International Medical University

Sunil Pazhayanur Venkateswaran

International Medical University

Puneet Agarwal

International Medical University

Abdul Rasyid Bin Sulaiman

International Medical University

Ismail Abdul Sattar Burud ( $\nabla$ ismail_burud@imu.edu.my )

International Medical University

\section{Research Article}

Keywords: Metacognition, correlation, students' estimated score, assessment, cognition, regulation

Posted Date: February 4th, 2022

DOI: https://doi.org/10.21203/rs.3.rs-1266966/v1

License: (9) This work is licensed under a Creative Commons Attribution 4.0 International License. Read Full License 


\section{Abstract}

Background: In the self-regulated learning theory, metacognition refers to "skills that enable learners to understand and monitor their cognitive process". Two categories of metacognition were described as knowledge of cognition and regulation of cognition. Metacognition skills enable learners to understand and monitor their cognitive processes. Metacognitive skills are necessary for curriculum delivery and should be taught. Students with metacognitive skills are expected to perform better and the present research provides evidence and recommends metacognition to be taught in future curriculum practice.

Methodology: Metacognition awareness inventory (MAI) score was collected to determine students' metacognitive skills in declarative, procedural, and conditional knowledge as well as the process involved in its planning, monitoring, and evaluation. Another purpose of this study was exploratory, to determine the validity of the MAl in terms of statistical relationship between metacognitive skills as knowledge of cognitive factor (KCF) and regulation of cognitive factor (RCF). Knowledge monitoring accuracy (KMA) as the difference between students' estimated Score (SES) versus actual knowledge on tests was also calculated, both in written OBA and EMQ (KMAW) and clinical tests OSCE (KMAC). MAI score was analyzed using Pearson correlation coefficient with academic achievement at the end of semester assessment (EOSA) both in written (EOSAW) and clinical (EOSAC) tests

Result: A mean score of 39.07 (6.68) for MAI and 24.13 (14.24) for KMAW and KMAC was found with a high standard deviation. A negative correlation between MAI and EOSAW (-0.029) and MAI and EOSAC $(-0.187)$, while a high correlation between MAI and KCF $=0.808$, MAI and RCF $(0.920)$ were found $(p<0.001)$. The correlation between KCF and RCF was moderately high $(0.559, p<.001)$. A negative correlation was also found between KMAW and EOSAW (-0.392). The correlation of EOSA achievement score and $\mathrm{KFC}$ and RCF was also negative at -0.002 and -0.100 respectively. A mixed insignificant $(p>0.05)$ correlation was among MAI, KMA, and SES for individual instruments.

Conclusion: A poor correlation of metacognitive skills and achievement scores indicates students' unrealistic self-evaluation of cognition for knowledge and regulation. This suggests curriculum delivery to incorporate students' awareness about metacognition in their learning process.

\section{Introduction:}

In self-regulated learning theory, metacognition refers to "skills that enable learners to understand and monitor their cognitive process". For successful learners' reflection, feedback, and awareness of their learning process is essential to handle and take control of one's learning. Reflective aspects of metacognition promote the self-efficiency of students' critical thinking and problem-solving skills. This awareness is referred to as metacognition and is of great importance in an educational context. The effects of self-efficacy beliefs on cognitive process take a range of forms and much human behaviour and goal setting are influenced by self-appraisal of capacity [1]. Self-efficacy is a personal judgment of one's capabilities to successfully perform a particular task [2]. For metacognitively aware students, the 
supervisor is a facilitator than a subject expert teacher and his job is to ensure analytic reasoning and problem-solving skills among the learners.

Metacognition is the ability to reflect upon, understand and control one's learning [3]. Two categories of metacognition were described as knowledge of cognition and regulation of cognition $[4,5,6]$. It can further be defined as what we know about our cognitive processes and how we use these processes to learn and remember. ${ }^{7}$ Our knowledge of cognition refers to what we know about how we learn; what we know about the procedures and strategies that are the most effective for us; and, what we know about the conditions under which various cognitive activities are most effective [8]. Planning involves setting out of a cognitive task by identifying appropriate strategies and cognitive resources. Monitoring looks at progress through a cognitive task and our ability to determine our performance. Subsequently, evaluating involves taking a look at learning outcomes and matching those learning outcomes with the program learning outcomes and that the regulatory processes were effectively used [8].

Knowledge of cognition is the reflective aspect of learning, what students know about themselves, strategies, and conditions under which strategies are most useful. Knowledge of cognition is further distinguished into three domains of declarative, procedural, and conditional knowledge together considered as the building blocks of conceptual knowledge. Declarative knowledge is about self and strategies, procedural knowledge is about how to use strategies and conditional knowledge is about, where and why to use strategies. Regulation of cognition is the control aspect of learning, the way students plan and implement their strategies as well as monitor and evaluate their learning. Regulation of cognition like knowledge of cognition is also broadly sub-grouped into planning, monitoring, and evaluation aspects $[9,18]$. A strong correlation between the knowledge of cognition and regulation of cognition factors suggests that knowledge and regulation complement each other to help students become self-regulated learners to achieve competency.

In curriculum delivery with students-centered learning, the onus of accountability is on students, and it is imperative to teach metacognitive skills in the classroom. The process can kick start with a metacognitive awareness inventory score in different domains of cognition to subsequently discuss the purpose and importance of a strategy taught in a classroom setting. Once the strategy is set for any given condition, the same strategy can be generalized to a new situation taking the knowledge of the cognitive domain from declarative to procedural and to another level of conditional knowledge. Students can learn from this discussion to know their current status of regulation of cognition in terms of planning, mentoring, and evaluation to improve their management of information and skills to become competent learners.

Metacognition in teaching and learning supports the acquisition, comprehension, retention, and application of what is learned. Good metacognitive skills support students to take responsibility for their learning to develop scientific concepts appropriately. Literature supports that metacognitively aware learners set learning strategies more effectively and perform better than unaware learners $[10,11]$. It 
allows individuals to plan, monitor, and evaluate their learning to improve their performance. There are two components of metacognition which include knowledge and regulation of cognition.

Cognition is often used synonymously with metacognition, the two differ in the sense that cognitive skills are about performing a task whereas metacognitive skills are about understanding how it is performed. Successful adult learners employ a range of metacognitive skills. Knowledge of cognition includes declarative, procedural, and conditional knowledge as building blocks of a conceptual map. Regulation of cognition corresponds to knowledge about the way students plan to implement strategies, monitor to correct comprehension errors, and evaluate to see the progress of their learning process. A strong correlation between these factors is likely to help students become self-regulated learners.

Students with well-developed metacognitive skills are expected to perform better than those without metacognition being involved in learning and teaching. Evidence to that can be provided by studying the correlation coefficient values of metacognition awareness inventory (MAI) score with that of individual assessment tools and broad-based assessment achievement scores. Metacognition is measured as metacognition awareness score as well as metacognitive knowledge and metacognitive regulation factors. To measure these scores some researchers use self-administered inventories and correlate them to students' performance as their academic achievement score $[3,12]$. Some other researchers have measured metacognitive skills as knowledge monitoring accuracy ability (KMA) as calibration performance at the local or global judgment. Calibration of performance measured as a local judgment of KMA is determined at item level as the difference between an actual score of items (question) on each test and the estimated score, how well a student performed on that item. Global judgment is determined after the entire test is completed and KMA is determined as the accumulative difference between the actual score and how well the student thinks they have performed in that test. Local KMA is thought to be a measure of ongoing metacognitive regulation during testing and global KMA is thought to be a measure of cumulative metacognitive regulation [13].

Metacognition skills play a pivotal role in the students-centered approach in which students are empowered to regulate their self-learning. How effectively this approach is implemented to achieve its outcome in many centres where it is practiced, is not clear. However, students' engagement in teaching and promotion of self-assessment and a self-sufficient approach improves learning and knowledge retention among the learners. This concept adds a new dimension to Miller's model of competency-based learning and this very concept brings the metacognition in learning (Figure 1). Changes in curriculum design to acquire competency need students to develop metacognitive skills for critical judgments with analytic reasoning and independent problem-solving. For a good learning practice, metacognitive skills are necessary to understand the learning process to accomplish successful curriculum delivery. The role of metacognitive skills to academic achievement is discussed keeping with the implication of future curriculum practice.

\section{Methodology:}


The research design is based on a cohort study of years 3 and 4 clinical students and the data was collected from the entire class of 84 students. However, 2 students did not complete the inventory and were excluded from the study. Metacognition Awareness Inventory (MAI), which examined the awareness of metacognitive skills among the clinical students, was used. The MAI score was collected as a reflection of students' metacognitive skills in terms of declarative, procedural, and conditional knowledge as well as planning, monitoring, and evaluation. The purpose of this study was to examine the relation between metacognitive skills of years 3 and 4 students recorded as metacognitive awareness inventory (MAI) score and broad-based measurement of academic achievement as end of semester (EOS) score. Another purpose of the MAI score was also to collect the baseline data to follow the students' progressive learning curve through the clinical years of semester 7 to semester 10 of the MBBS Program in a private medical school.

Another purpose of this study was exploratory, to determine the validity of MAl in terms of statistical relationship between metacognitive skills as knowledge of cognitive factor (KCF) represented with 17 items and regulation of cognitive factor (RCF) represented with 35 Items. KCF is further divided into 3 categories, declarative knowledge with 8 items, procedural knowledge with 4 items, and conditional knowledge with 5 items. RCF, on the other hand, is further divided into 5 categories however, the authors accounted RCF for 3 categories of planning with items, monitoring with items, and evaluation with items. This made us contemplate 37 items in total to be considered in KCF and RCF out of a total 52 items of MAI. Knowledge monitoring accuracy (KMA) as the difference between students' estimated vs. actual knowledge on tests was also calculated. MAl score was analysed using Pearson correlation coefficient with academic achievement in end of the semester assessment (EOSA) in different assessment instruments of written test (OBA, EMQ) and clinical test (OSCE).

\section{Results:}

For the 84 respondents, the MAI Mean (SD) score was 39.07 (6.68). The Mean (SD) score for the knowledge of cognition factor (KCF), regulation of cognition factor (RCF), and KMA were 11.52 (2.92), 27.41 (4.95), and 24.13 (14.24) respectively (Table 1).

Table 1

Descriptive statistics (Mean and SD) of MAI, KMA, KCF and RCF score.

\begin{tabular}{|lll|}
\hline Variable & Mean & Standard Deviation \\
\hline MAI Total Score (MAI) & 39.07 & 6.68 \\
\hline KMA Total Score (written and Clinical) & 24.13 & 14.24 \\
\hline Knowledge of Cognition Factor (KCF) & 11.92 & 2.92 \\
\hline Regulation of Cognition Factor (RCF) & 27.41 & 4.95 \\
\hline
\end{tabular}

A poor correlation was observed between MAI and KMA $(0.134 P=0.223)$ however, a highly significant correlations between MAI and KFC $(0.808 p=<0.001)$ and MAI and RFC $(0.920 p=<0.001)$ respectively 
was found. The trend continued to be a poor correlation between KMA and KCF $=0.178(0.106)$ and $\mathrm{KMA}$ and RCF $=0.109$ (0.323) however, positive (Table 2).

Table 2

Correlation between $\mathrm{MAI} / \mathrm{KMA} / \mathrm{KFC} / \mathrm{RCF}$ Scores

\begin{tabular}{|lllll|}
\hline Variables & MAI Score & KMA Score & KCF & RCF \\
& $\mathbf{N}=\mathbf{8 4}$ & $\mathbf{N}=\mathbf{8 4}$ & $\mathbf{N}=\mathbf{8 4}$ & $\mathbf{N}=\mathbf{8 4}$ \\
\hline MAI & 1 & $.134(.223)$ & $.808(<.001)$ & $.920(<.001)$ \\
\hline KMA & $.134(.223)$ & 1 & $.178(.106)$ & $.109(.323)$ \\
\hline KCF & $.808<.001)$ & $.178(.106)$ & 1 & $.559(<.001)$ \\
\hline RCF & $.920(<.001)$ & $.109(.323)$ & $.559(<.001)$ & 1 \\
\hline
\end{tabular}

A negative correlation between MAI and EOSA in written exams (EOSW) and EOSA in the clinical exam (EOSC) have been -0.029 (796) and -0.187 (.088). A similarly negative correlation between MAI and a student's estimated score total (SEST) was $=-0.006(0.958)$. A positive though but poor correlation between MAI and students' estimated score in written exam (SESW) was $=0.007$ (952) however, the student's estimated score in clinical exam (SESC) remained negative $=-0.033(0.765)$ (Table 3).

Table 3

Correlation between MAI/KMA KCF/RCF scores and SES of written and clinical tests.

\begin{tabular}{|c|c|c|c|c|c|c|}
\hline Variable & $\begin{array}{l}\text { EOSW } \\
\text { Score } \\
(N=84)\end{array}$ & $\begin{array}{l}\text { EOSC } \\
\text { Score } \\
(N=84)\end{array}$ & $\begin{array}{l}\text { EOS Total } \\
\text { Score } \\
(\mathbf{N}=84)\end{array}$ & $\begin{array}{l}\text { SES } \\
\text { Written } \\
(\mathrm{N}=\mathbf{8 4})\end{array}$ & $\begin{array}{l}\text { SES } \\
\text { Clinical } \\
(\mathrm{N}=\mathbf{8 4})\end{array}$ & $\begin{array}{l}\text { SES } \\
\text { Total } \\
(\mathrm{N}=\mathbf{8 4})\end{array}$ \\
\hline MAI & .099 (.369) & $-.044(.689)$ & $-.074(.501)$ & .007 (.952) & $\begin{array}{l}-.033 \\
(.765)\end{array}$ & $\begin{array}{l}-.006 \\
(.958)\end{array}$ \\
\hline KMA & $\begin{array}{l}-.392 \\
(<.001)\end{array}$ & $-.234(.032)$ & $-.068(.537)$ & $\begin{array}{l}-.235 \\
(.031)\end{array}$ & $\begin{array}{l}-.024 \\
(.831)\end{array}$ & $\begin{array}{l}-.194 \\
(.077)\end{array}$ \\
\hline KCF & $.037(.736)$ & $.117(.290)$ & $-.002(.988)$ & $.018(.869)$ & $\begin{array}{l}-.055 \\
(.618)\end{array}$ & $.004(.971)$ \\
\hline $\mathrm{RCF}$ & $-.060(.590)$ & $.189(.085)$ & $-.001(.366)$ & $\begin{array}{l}-.015 \\
(.894)\end{array}$ & $\begin{array}{l}-.046 \\
(.677)\end{array}$ & $\begin{array}{l}-.027 \\
(.807)\end{array}$ \\
\hline
\end{tabular}

A similar poor correlation between MAI and individual assessment tools was observed for OBA $=-0.063$ $(0.571)$ and for $\mathrm{EMQ}=0.003(0.987)$ and OSCE $=-0.187(0.088)$ respectively (Table 4). 
Table 4

Correlation between $\mathrm{MAI} / \mathrm{KMA} / \mathrm{KCF}$ and RCF score and the individual assessment tool achievement and estimated scores.

\begin{tabular}{|c|c|c|c|c|c|c|}
\hline Variable & $\begin{array}{l}\text { OBA } \\
(N=84)\end{array}$ & $\begin{array}{l}\text { EMQ } \\
(\mathrm{N}=\mathbf{8 4})\end{array}$ & $\begin{array}{l}\text { OSCE } \\
(\mathrm{N}=\mathbf{8 4})\end{array}$ & $\begin{array}{l}\text { SES OBA }(\mathrm{N}= \\
84)\end{array}$ & $\begin{array}{l}\text { SES EMQ (N = } \\
\text { 84) }\end{array}$ & $\begin{array}{l}\text { SES OSCE } \\
(\mathrm{N}=\mathbf{8 4})\end{array}$ \\
\hline MAI & $\begin{array}{l}-.063 \\
(.571)\end{array}$ & $\begin{array}{l}.003 \\
(.978)\end{array}$ & $\begin{array}{l}.187 \\
(.110)\end{array}$ & $.015(.893)$ & $-.002(.987)$ & $\begin{array}{l}-.033 \\
(.765)\end{array}$ \\
\hline KMA & $\begin{array}{l}.092 \\
(.403)\end{array}$ & $\begin{array}{l}.089 \\
(.418)\end{array}$ & $\begin{array}{l}-.044 \\
(.689)\end{array}$ & $-.165(.134)$ & $-.242(.027)$ & $\begin{array}{l}-.024 \\
(.831)\end{array}$ \\
\hline KCF & $\begin{array}{l}.023 \\
(.812)\end{array}$ & $\begin{array}{l}.043 \\
(.131)\end{array}$ & $\begin{array}{l}-.117 \\
(.290)\end{array}$ & $.060(.588)$ & $-.021(.849)$ & $\begin{array}{l}-.055 \\
(.618)\end{array}$ \\
\hline RCF & $\begin{array}{l}.003 \\
(.979)\end{array}$ & $\begin{array}{l}.050 \\
(.711)\end{array}$ & $\begin{array}{l}.189 \\
(.085)\end{array}$ & $-.189(.946)$ & $.017(.874)$ & $\begin{array}{l}-.046 \\
(.677)\end{array}$ \\
\hline
\end{tabular}

A negative correlation persisted between knowledge of monitoring accuracy (KMA) and end

of the semester assessment in written (EOSW) and clinical (EOSC) scores as $-0.099(0.369)$ and -0.044 (0.689) respectively (See Table 3). Correlation between SES for EOSW test positive $=0.007$ (0.952) was again found negative for EOSC test $=-0.033(0.765)$. A similarly negative correlation between KMA and individual assessment tools of OBA, EMQ, and OSCE continues to be = 0.092 (403), 0.089 (418), and $-0.044(.689)$ respectively in all three individual assessment tools (See Table 4). And the trend continued to be negative for SES and all the three individual instruments of OBA, EMQ, and OSCE $=-0.165(0.134)$, -0.242 (0.027), and -0.024 (9.831) respectively (See Table 4).

A positive, though poor, correlation was found between the KCF and EOSW test $=0.037(0.736)$. However, correlations between KCF and EOSC test remained negative $=-0.117(0.290)$. On the other hand, correlations between RCF and EOSW and EOSC tests were negative as usual $=-0.060(0.590)$ and -0.189 (0.085) respectively (See Table 3 ). Looking back into KCF and individual tests, scores were poor, however, positive for OBA $=0.023(0.835), \mathrm{EMQ}=0.043(0.698)$ but negative for OSCE $=-0.021(0.849)$. But for RCF correlations between $\mathrm{OBA}=-0.099(0.370)$ and $\mathrm{EMQ}=-0.019(0.864)$ remained negative as the overall trend. Same trend was further observed with a positive but poor correlation was observed between KCF and SES OBA $=0.060(0.588)$, SES EMQ as negative $=-0.021(0.849)$ and SES OSCE $=-0.055(0.618)$ respectively (See Table 4).

\section{Discussion:}

The current study intended to explore MAI and its relationship to a single and broad measure achievement score of students before entering a private medical school and their performance in their end-of-semester examinations. Metacognition is considered an extended and important component of a structured learning model from the acquisition of knowledge to the application of knowledge. 
Metacognition is imperative to successful learning, which needs individuals to reflect on their existing cognitive skills with their strengths and weaknesses and to apply corrective measures by constructing new cognitive skills. Honest self-assessment is recognized as an important contributor to the development of critical capacity, reflective attitude, and autonomous life-long learning. ${ }^{14,15}$ Some studies $^{3,12}$ have shown significant correlations between broad measure achievement score and MAI as well as achievement score and knowledge of cognition and regulation of cognition. Yet other studies suggest good correlations between achievement score and regulation of cognition but not between achievement score and knowledge of cognition. ${ }^{16}$ The present study, on the contrary, has shown a good correlation between MAl, knowledge of cognition as well as regulation of cognition however, poor correlations with achievement scores (See Table 2, 3, and 4). A correlation was shown between MAl, knowledge of cognition, and regulations of cognition factors. These were the only significant positive correlations in the current study (See Table 2) suggesting the validity of metacognitive inventory items for its overall score versus KCF and RCF components.

The poor correlation between students' perceptions of metacognitive skills and their achievement scores is a challenge for the faculty and the effectiveness of curriculum delivery. This demands metacognition to be taught as a generalized skill to enable the students to set their learning strategies. A mixed pattern of MAI score documented on metacognition awareness with poor relevance to their performance at the end of summative assessment (See Table 3 ) is an indication to make them aware of what they think about their learning process and what exists in reality. Introduction to metacognition as a skill to strategize learning must be well understood by the students for all the aspects of knowledge of cognition and regulation of cognition. In the present study, MAI was completed without being well understood for its critical value and score of each item. Students while completing the inventory placed them on the higher and positive side of what items were meant to describe their real characteristics. MAI without being understood for its value was most likely considered to implicate their achievement score on the test.

The Metacognitive Awareness Inventory (MAl) could be used to begin discussions to help improve experiential learning towards competency-based education. As the first step to practice metacognition, it is important to acknowledge its existence and that it is different from cognition. The promotion of metacognitive awareness among learners may enhance academic achievement. The next step is to teach strategies to help students construct explicit knowledge about when and where to use strategies. Finally, a flexible strategy can be used to make careful regulatory decisions that enable students to plan, monitor, and evaluate their learning. Poor correlation between MAI and students' achievement scores (See Table 2 and 3 ) is an alarming indicator of necessary corrective measures in the implementation of the curriculum with an explicit teaching session in metacognition.

The poor correlation coefficient between MAI and the students' achievement score in EOSA and individual assessment tools (See Table 3 and 4 ) in this study are indicating the problems of effective curriculum delivery. The purpose of this study was to examine the relation between MAI score and EOSA score, a broad measure assessment, and individual tests score (SeeTable 3 and 4). Poor correlation between MAI 
and end of the semester assessment and a negative correlation between MAI and most of the assessment tools as well as students estimated scores on EOSA in written and clinical tests of the individual assessment suggest students' unrealistic self-evaluation of their cognition in terms of knowledge and regulation of cognition, the so-called metacognition. The MAI score was also used to analyse the relationship between metacognitive skills and specific measures of assessment test (See Table 4) both in written knowledge of objective test (OBA and EMQ) and subjective test (OSCE). An insignificant low correlation has been found between them. Comparatively better but insignificant correlation $(p=<0.05)$ in terms of MAI and OSCE score may be attributed to their mastery of a limited number of procedures in the skills domain than more extensive content in the domain of written knowledge.

Another purpose of this study was exploratory to determine the validity of MAl in terms of statistical relationship between metacognitive skills as knowledge of cognitive factor (KCF) and regulation of cognitive factor (RCF), which was significantly correlated (see Table 2). The correlation between metacognitive knowledge and metacognitive regulation in terms of knowledge of cognition factor (KCF) and regulation of cognition factor (RCF) was found highly correlated however, researchers have shown that metacognitive knowledge may develop independently of metacognition of regulation. ${ }^{17}$ The actual test of performance (EOSA) achievement score on written tests (OBA and EMQ) and clinical test (OSCE) poorly and often negatively correlated with metacognition of knowledge score (KCF) than metacognition of regulation score (RCF) and are not consistent with literature findings. This could be due to students' underestimating their metacognitive skills.

Calibration of students' performance as knowledge monitoring accuracy or ability (KMA) was measured as a difference between students' estimated versus actual knowledge on tests. KMA determines the students' monitoring of their knowledge in terms of regulation of cognitive factor (RCF). A poor correlation between KMA and EOSA assessment scores of OBA and EMQ, though positive has been determined to be negatively correlated was an unexpected finding (See Table 4) and can be attributed to students' lack of confidence about assessment, testing the higher-order thinking skills.

Another interesting finding in the current study was the correlations between the students' estimated scores in EOSA of individual assessment instruments and the actual achievement scores in these instruments. A poorly correlated student estimated score (SES) in written and clinical scores on individual tests scores of EOSA is an obvious lack of metacognitive skills among the students (Table 5). 
Table 5

Correlation between KMA individually calculated assessment tools' scores and the corresponding SES

\begin{tabular}{|c|c|c|c|c|c|c|}
\hline \multirow[t]{2}{*}{ Variable } & \multirow[t]{2}{*}{ OBA Score } & \multirow[t]{2}{*}{ EMQ Score } & \multirow{2}{*}{$\begin{array}{l}\text { OSCE } \\
\text { Score }\end{array}$} & SES & SES & SES \\
\hline & & & & OBA & EMQ & OSCE \\
\hline KMA OBA & $\begin{array}{l}-.009 \\
(.938)\end{array}$ & - & - & $\begin{array}{l}-.243 \\
(.0260\end{array}$ & - & - \\
\hline KMA EMQ & - & $\begin{array}{l}.363 \\
(<.001)\end{array}$ & - & - & $\begin{array}{l}-.632 \\
(<.001)\end{array}$ & - \\
\hline $\begin{array}{l}\text { KMA } \\
\text { OSCE }\end{array}$ & - & - & $-.082(.457)$ & - & - & $.085(.439)$ \\
\hline
\end{tabular}

Some of these negative correlations are quite alarming about what students think about their thinking, how they estimate their performances even in those undertaken assessment tools immediately after the test. The correlation between MAI and KMA of individual measurement tools shows MAI slightly better correlated with the test of knowledge than the clinical test of OSCE and SES of all the individual test instruments. This indicates students' overestimation of their metacognitive abilities than what they have.

The findings of the present study emphasise the importance of metacognition in learning. Teaching and learning should be delivered in a way to encourage metacognition that has a relevant and effective impact on students' achievement score. Metacognition plays a significant role in meaningful learning. Therefore, it is imperative to redesign the curriculum and its delivery with emphasis on developing awareness, enhancement, and practice of metacognitive skills among the students to become competent learners. Once they become aware to recognize their metacognitive skills, in reality, they may become able to generalize those skills to apply in a different situation encountered in learning specially in emergency remote teaching with unprecedented challenges of Covid-19 like pandemics in the future.

\section{Conclusion:}

For a good learning practice, metacognitive skills are necessary to understand the learning process to accomplish tasks in routine teaching and learning activities. It also affects the outcome learning as selfefficiency of students' critical thinking and problem-solving skills. Good metacognitive skills support students to take responsibility for their learning to develop scientific concepts appropriately. The poor correlation between students' perceptions of metacognitive skills is a challenge for the faculty and demands curriculum delivery to incorporate students' awareness about metacognition in their learning process.

\section{Declarations}

1. Availability of data and material: Raw data included in the manuscript is provided as a supplementary file 


\section{Ethics approval and consent to participate section:}

(A) Ethical Approval - The study was approved by the Internationa Medical University Joint Committee on Research and Ethics

(B) Accordance: - The Authors confirm that all methods were carried out following relevant guidelines and regulations of Declarations of Helsinki.

(C) Informed Consent: - Informed consent was obtained from all subjects before conducting the study

\section{Consent for publication:- Not Applicable}

4. Competing interests: No conflict with anyone at the individual or institutional level with regards to content and material used in this manuscript. The authors have no conflict of interest and anything to declare.

5. Funding: The research proposal was presented in 173rd IMU Joint Committee on

Research and Ethics on 13th December 2018 and was given full approval with

reference No. 4.20/JCM-173/2018 and Project ID no: IMU 424/2018.

\section{Authors' contributions:}

Author $\mathrm{SH}$ is the principal researcher $(\mathrm{PI})$ in this research project, who has

written the proposal together with the other four co-researchers and defended the

proposal in the IMU Joint Committee for Research and Ethics (IMU-JC). SH analysed the data collected and wrote the manuscript, which was reviewed by the other authors.

Author SPV has contributed to collating the data and calculating the various aspects of the Metacognitive Awareness Inventory (MAI). He has also been engaged in reviewing the manuscript. PA, ARBS, and IASB have played a very important role in enrolling the students into the research study, administration of MAl, and collecting the inventory from the students. All authors read and approved the final manuscript. IASB was also engaged in reviewing the manuscript and is also the corresponding author.

\section{Acknowledgment.}

The authors would like to thank the International Medical University for the support and grant given to conduct the study with project ID 424/2018.

\section{References}


1. Khan A, Cansever Z, Avsar U, Acemoglu H. Perceived Self-Efficacy and Academic Performance of Medical Students at Ataturk University, Turkey. Journal of the College of Physicians and Surgeons Pakistan. 2013;23:495-498.

2. Dijkstra J, Van der Vleuten C, Schuwirth L. A new framework for designing programmes of assessment. Advances in Health Sciences Education: Theory and Practice. 2010;15:379-393.

3. Schraw G, Dennison R. Assessing metacognitive awareness. Contemporary Educational Psychology. 1994;19:460-475.

4. Brown A. Metacognition, executive control, self-regulation, and other more mysterious mechanisms. In: Weinert F, Kluwe R, ed. by. Metacognition, motivation and understanding. Hillsdale, N.J: Erlbaum; 1987. p. 65-116.

5. Flavell J. Speculations about the nature and development of metacognition. In: Weinert F, Kluwe R, ed. by. Metacognition, motivation and understanding. Hillsdale, N.J: Erlbaum; 1987. p. 21-29.

6. Jacobs J, Paris S. Children's Metacognition About Reading: issues in Definition, Measurement, and Instruction. Educational Psychologist. 1987;22(3):255-278.

7. Ormrod J. Human Learning. 4th Ed. Upper Saddle River, N.J.: Pearson; 2004.

8. Schraw G, Moshman D. Metacognitive Theories. Educational Psychology Review, 1995;7(4):351371.

9. Artzt A, Armour-Thomas E. Development of a cognitive metacognitive framework for protocol analysis of mathematical problem-solving in small group. Cognition and Instruction. 1992;9:137175.

10. Garner R, Alexander P. Metacognition: Answer and unanswered question. Educational Psychologist. 1989;24:143-158.

11. Preseley $M$, Ghatala E. Self-regulation learning: Monitoring learning from text. Educational Psychology. 1990;25:19-33.

12. Sperling R, Howard B, Staley R, DuBois N. Educational Research and Evaluation. 2004;10(2):117139.

13. Nietfeld J, Cao L, Osborne J. Metacognitive monitoring accuracy and student performance in the postsecondary classroom. The Journal of Experimental Education. 2005;74(1):7-28.

14. Cambra-Fierro J, Cambra-Berdun J. Students' self-evaluation and reflection (Part 2): An empirical study. Education \& Training. 2007;49:103-111.

15. McDonald B, Boud D. The impact of self-assessment training on performance in external examinations. Assessment in Education. 2003;10:209-220.

16. Andria $Y$, Jane D. Metacognition awareness and academic achievement in college students. Journal of the Scholarship of Teaching and Learning. 2008;8(2):1-10.

17. Schraw G. The effect of knowledge on local and global monitoring. Contemporary Educational Psychology. 1994;19:143-154. 
18. Baker L. Metacognition, comprehension monitoring, and adult reader. Educational Psychology Preview. 1989;1:3-38.

\section{Figures}

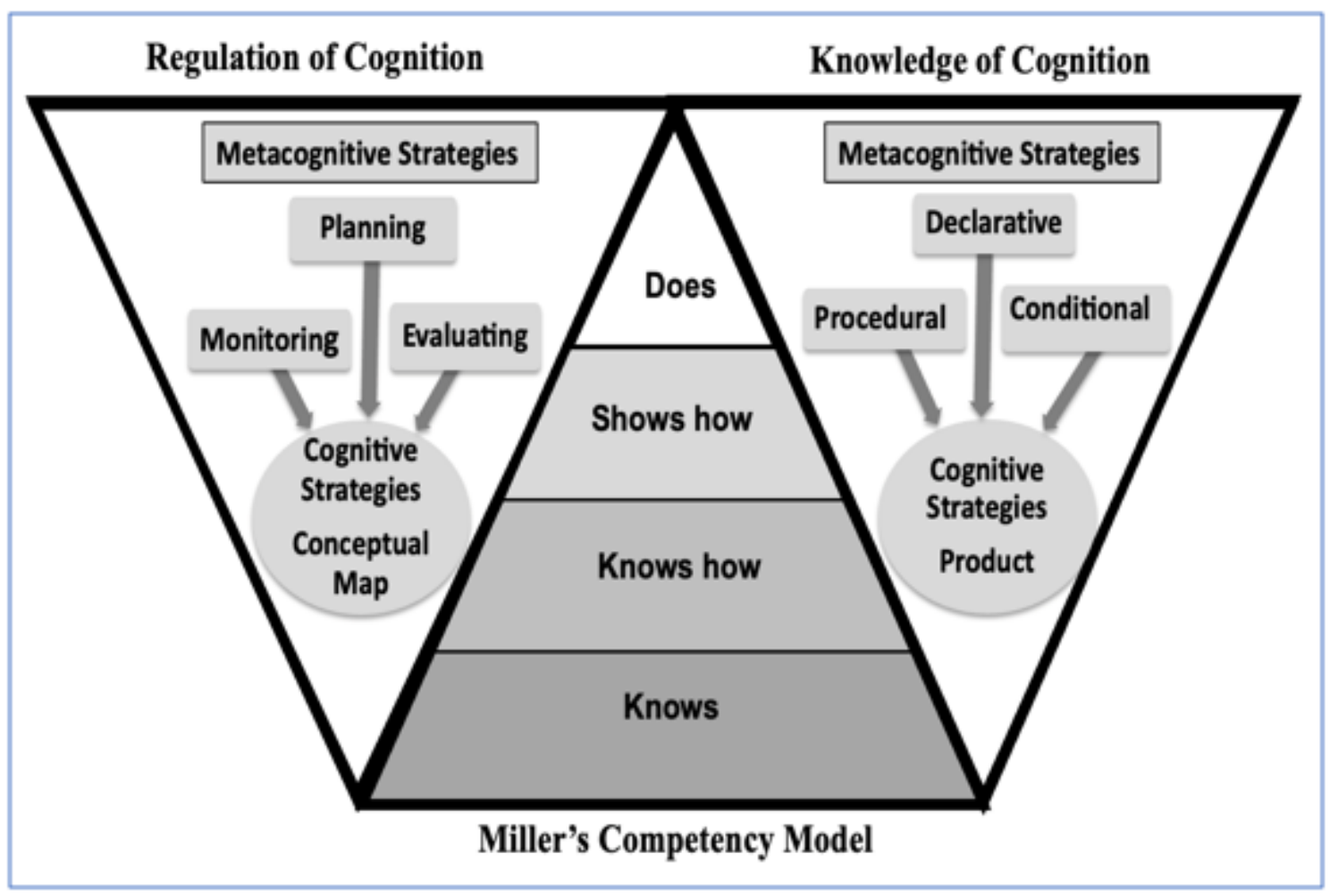

Figure 1

Metacognition as knowledge of cognition and regulation of cognition aligned with Miller's competency model.

\section{Supplementary Files}

This is a list of supplementary files associated with this preprint. Click to download.

- MetacoagnitionData.xlsx 